\title{
How to Treat Chronic Subdural Hematoma? Past and Now
}

\author{
Kyeong-Seok Lee, M.D. \\ Department of Neurosurgery, Soonchunhyang University Chonan Hospital, Chonan, Korea
}

Treatment of chronic subdural hematoma (CSDH) is relatively straightforward, however, there is still some debate regarding the best strategy for treatment. The most practical recommendations of up to date were identified by a review of literature. The author reviewed the literature on CSDH management from the past to now to identify the best methods. Till 1970s, craniotomy was the most commonly used method. Burr hole (BH) became the most preferred method from 1980s. In 1977, twist drill (TD) craniostomy was introduced. Closed system drainage after a BH or a TD became the most frequently used surgical method. Although nonsurgical treatment is often successful, trephination has more advantages, such as rapid resolution of the symptoms and short period of hospitalization. Nonsurgical treatment is possible in asymptomatic patients with a small CSDH. For the symptomatic patients with $\mathrm{CSDH}$, trephination is the treatment of choice, either by BH or TD. In gray zone between surgery and medical treatment, shared decision making can be an ideal approach. For the recurrent CSDHs, repeated trephination is still effective for patients with a low risk of recurrence. If the risk of recurrence is high, additional management would be helpful. For the refractory CSDHs, it is necessary to obliterate the subdural space.

Key Words : Hematoma, Subdural, Chronic · Craniotomy · Trephining · Conservative treatment · Recurrence · Craniocerebral trauma.

\section{INTRODUCTION}

Treatment of chronic subdural hematoma (CSDH) has improved dramatically in recent years because of advances in diagnosis and surgical techniques. However, there is still some debate regarding the best strategy for treatment ${ }^{20,72,97)}$. There are numerous modifications or alternative methods to reduce the recurrence rate, however, the efficacy is still controversial. The author tried to find the most practical recommendations of up to date.

\section{MATERIALS AND METHODS}

The author reviewed the literature on CSDH management from the past to now to identify the best methods.

\section{RESULTS}

\section{The past}

There was a report that the first trephination for CSDH was made by Hulke in 19th century ${ }^{94)}$. In the 1860s and 1870s, the most successful skull surgery in the world was done by some native surgeons in the South Pacific, the 'wise men' of Tolai

- Received : July 9, 2018 •Accepted : July 16, 2018

- Address for reprints : Kyeong-Seok Lee, M.D.

Department of Neurosurgery, Soonchunhyang University Chonan Hospital, 31 Suncheonhyang 6-gil, Dongnam-gu, Cheonan 31151, Korea Tel : +82-41-570-3652, Fax : +82-41-572-9297, E-mail : ksleens@sch.ac.kr

This is an Open Access article distributed under the terms of the Creative Commons Attribution Non-Commercial License (http://creativecommons.org/licenses/by-nc/4.0) which permits unrestricted non-commercial use, distribution, and reproduction in any medium, provided the original work is properly cited. 
tribe of New Guinea ${ }^{54)}$. Even though the mortality rate of one of Tolai surgeons was 8 or $25 \%$, which compared with a mortality of 75\% in London teaching hospitals in late 19th centu$\mathrm{ry}^{45)}$, no one could remember any names of the wise men. In a report of $1930^{18)}$, the recognized treatment of CSDH was craniotomy, although it could be managed by trephination. Till 1970s, craniotomy with or without removal of the membrane was more frequently used ${ }^{30)}$ than dual cranial perforations ${ }^{23)}$ or trephination with irrigation ${ }^{33)}$. Before cerebral angiography, it was hard to localize the hematoma. Exploratory burr-hole (BH) was an option to find the hematoma till 1960s. It looks like a 'woodpecker surgery ${ }^{35)}$, however, this type of surgery might save a life. Woodpecker surgery of exploratory BHs disappeared after introduction of computerized tomographic (CT) scans in $1973^{14)}$. Since CSDH is consisted of mainly liquefied blood, trephination alone is usually sufficient to remove the lesion. While craniotomy requires general anesthesia and much more time to resect a bone flap and replace it, which may cause complications. In 1975, a simple technique was reported to make a hole by an $18 \mathrm{G}$ spinal needle ${ }^{60)}$. However, making a hole with a spinal needle was not simple to be used widely. In 1977, twist drill (TD) craniostomy was published ${ }^{84}$. This technique was possible under local anesthesia even at the bedside. After 1980, trephination either by BH or TD became more popular than craniotomy. Closed system drainage after a $\mathrm{BH}$ or a TD became the most frequently used surgical treatment of $\mathrm{CSDH}^{15,52,83)}$. To precipitate drainage, application of negative pressure to a catheter in the subdural space may result plugging by brain tissue or meninges, while larger catheters may provoke seizures ${ }^{28)}$. In 1999, a minimal invasive device was developed to evacuate CSDH, called subdural evacuating port system (SEPS) ${ }^{22}$, which was safe and effective as TD craniostomy ${ }^{6,37,40,59,74,77)}$. Removal of the hematoma was possible by a TD with or without a hollow screw under local anesthesia as a bedside procedure. Although a much smaller hollow screw, $3 \mathrm{~mm}$ in diameter, was developed $^{91)}$, the smaller does not always seem to be the better.

\section{Now}

Systematic reviews and metaanalyses suggested that the use of TD was better or at least equivalent to BHs in recurrence rates or other outcome ${ }^{2,34,50,56)}$. Bedside TD with closed system drainage for 48 hours $^{34)}$ is a safe and effective first-line management option ${ }^{2)}$.
Management of CSDH is variable (Table 1). In general, the decision to operate is influenced both by the radiographic appearance of the lesion as well as by the patient's neurological exam $^{20}$. The spontaneous resolution or medical treatment of CSDHs has been well documented ${ }^{21,36,38,63,80)}$. However, hospitalization ranged from 3 weeks to 42 days in some reported series and some patients eventually underwent surgery ${ }^{25,89)}$.

\section{Non-surgical treatment}

Inappropriate treatment was common in the earlier period, when they did not know the cause, natural history and pathophysiology of this lesion. In 1920s, lumbar puncture was the only definite non-operative treatment that had been recommended ${ }^{67}$. Although spontaneous resolution of CSDH was sparsely reported, the first remark about a nonsurgical treatment of CSDH was given by Ambrosetto ${ }^{3)}$ in 1962 . He described four patients, who received a conservative multimodal therapy in combination with corticosteroids. In 1970, a nonsurgical treatment consisting of osmotherapy with $20 \%$ mannitol was reported ${ }^{82)}$. The theoretical basis for osmotherapy is that mannitol and hypertonic glucose facilitate the resorption of the hematoma through the increase in the osmotic pressure of the blood. However, osmotherapy was discontinued after a failure of the mannitol therapy in a controlled clinical trial ${ }^{26)}$. There were some reports that nonsurgical treatment with bed rest, steroids ${ }^{17)}$, mannitol ${ }^{10)}$, or a combination was successful. Successful management was also reported with some drugs inhibiting bleeding or inflammation such as angiotensin converting enzyme inhibiter ${ }^{93)}$, atorvastatin ${ }^{90)}$, and tranexamic acid $^{36)}$. Stopping the anti-coagulants or radiation was also effective to resolve the hematoma ${ }^{65,68)}$. Nonsurgical treatment was successful for patients with age greater than 70 years, decreased cognitive level, brain atrophy, and absence of increase

Table 1. Variable methods of treatment for chronic subdural hematomas

\begin{tabular}{|c|c|}
\hline Group & Value \\
\hline Non-surgical & $\begin{array}{l}\text { Bed rest }^{31)} \text {, steroids } \\
\text { tranexamic acid } \\
\text { 12,736) }\end{array}$ \\
\hline $\begin{array}{l}\text { Minimally invasive } \\
\text { surgery }\end{array}$ & $\begin{array}{l}\text { Twisted drill craniostomy } y^{32)}, \text { burr hole } \\
\text { trephination, endoscope } e^{13,29)}\end{array}$ \\
\hline Traditional surgery & Craniotomy, craniectomy \\
\hline Uncommon methods & $\begin{array}{l}\text { Subdural tap, subduroperitoneal } \\
\text { shunt, subgaleal reservoir, reduction } \\
\text { cranioplasty, middle meningeal artery } \\
\text { embolization }\end{array}$ \\
\hline
\end{tabular}


of intracranial pressure ${ }^{63)}$. Favorable factors for conservative treatment were female sex, lesser midline shift, lesser thickness of the hematoma, and lesser attenuation values on CT $\operatorname{scan}^{86)}$. However, it is unclear whether the resolution really result from the drug effect or natural course. Furthermore, nonsurgical treatment frequently requires close observation with repeated CT scans for a long time, average 40 days $^{38)}$. Surgical treatment for $\mathrm{CSDH}$ is quite simple to do at the bedside under local anesthesia. Compared to nonsurgical treatment, trephination by either a $\mathrm{BH}$ or a TD has more advantages, such as rapid resolution of the symptoms and short period of hospital admission. Avoiding surgery can't be the goal of CSDH management.

\section{Surgical treatment}

Nonsurgical treatment may be possible in a few asymptomatic patients with a small CSDH. It requires a long apprehensive monitoring, however. Trephination is a relatively simple, safe, and effective procedure to manage this condition. Not all patients with $\mathrm{CSDH}$ requires surgery. In general, the decision to operate is based on the presence of symptoms and clinical or imaging signs of cerebral compression. Of course there is a gray zone between surgery and medical treatment. It may be difficult to decide a certain therapy for an asymptomatic patient with a significant amount of CSDH, or a patient with an obscure symptom and a small CSDH. Decision making may be different from the doctors ${ }^{8)}$. In general, neurosurgeons prefer surgery while neurologists prefer medical therapy ${ }^{11)}$. In this situation, so called shared decision making is the method of choice. Through shared decision making, clinicians can help patients understand the importance of their values and preferences in making the decisions that are best for them ${ }^{7)}$. Doctors should provide information on the natural history, predicted prognosis, risk and benefits of a certain therapy, and so on. Although the fate of $\mathrm{CSDH}$ depends on the pre-morbid status, the dynamics of absorption-expansion and maturation of the neomembrane ${ }^{46)}$, however, the natural history of a certain CSDH remains unclear. Patients who have minimal neurological deficits and lesions of small size with low or isodensity and ventricular dilatation on CT have a greater chance for spontaneous resolution of their hematoma ${ }^{57)}$. Medical therapy can be an alternative for patients with mild symptoms and frontal hematomas ${ }^{31}$, or patients with a premorbid condition not allowing surgical evacuation of $\mathrm{CSDH}^{78)}$. Shared decision making can be an ideal approach to clinician-patient decision making, improve the quality of medical decisions, and reduce costs $^{62)}$. A scoring system ${ }^{42)}$ can be a useful tool to predict outcome and result of surgical intervention.

\section{SURGICAL METHODS AND ANESTHESIA}

The most commonly used surgical methods are TD craniostomy, BH trephination, and craniotomy. They have their own advantages and disadvantages (Table 2). Openings of the skull up to a diameter of $5 \mathrm{~mm}$ were categorised as TD craniostomy, openings of up to $30 \mathrm{~mm}$ as $\mathrm{BH}$ craniostomy, and larger openings as craniotomy ${ }^{95)}$.

It is difficult to identify the most effective surgical method for CSDH. A study by decision analysis reported that the $\mathrm{BH}$ is the most efficient choice for surgical drainage of uncomplicated $\mathrm{CSDH}^{48)}$. An evidence based review ${ }^{2)}$ revealed no difference in the cure rates and mortality among the three techniques. The authors concluded that $\mathrm{BH}$ provided the best cure-to-complication ratio, since TD had a significantly higher rate of recurrence and craniotomy had higher morbidity. A systematic review and meta-analysis with 34829 patients revealed no significant difference in the rate of cure, recurrence, morbidity, or mortality between TD and $\mathrm{BH}^{2)}$. They recommended bedside TD as a relatively safe and effective first-line

Table 2. Characteristics of three operative methods

\begin{tabular}{|c|c|c|c|}
\hline Item & Craniotomy & Burr hole & Twist drill \\
\hline Anesthesia & General & General or local & Local or general \\
\hline Place & Operating room & Operating room or bedside & Bedside or operating room \\
\hline Operation time & Around 3 hours & Around 1 hour & Less than 1 hour \\
\hline Complications & High & Low & Low \\
\hline Recurrence & Low & Slightly high & High (?) \\
\hline
\end{tabular}


management option. Although there are diverse practices in detail, vast majority of CSDH can be treated either by TD or $\mathrm{BH}^{75)}$. Most surgeons would choose the familiar method ${ }^{47)}$. As the first-line treatment option, TD is the best, since it can be done at the bedside under local anesthesia, which saves health cost and eliminate perioperative risks related to general anesthesia. BH may be an alternative of TD. Since craniotomy was found to result in a higher complications, it should be reserved for solid, organized or calcified hematomas. Actually in a retrospective study, craniotomy result longer operation time, longer hospital stay with more complications and higher cost. Craniotomy seems to be necessary for the organized or calcified CSDH, when the CSDH is manifested by seizure or hemiparesis. Headache alone is hard to be a relevant symptom of the longstanding organized CSDH, although it is the third most frequent symptom of $\mathrm{CSDH}^{98)}$. In calcified CSDHs, observation is recommended for asymptomatic patients or patients with a headache alone. Although Markwalder had recommended craniotomy for recurrent $\mathrm{CSDH}$, solid hematoma, or failure of the brain re-expansion ${ }^{52)}$, solid consistency of the hematoma might be the only indication of craniotomy. Most recurrent subdural hematomas can be managed successfully via $\mathrm{BH}$ with closed-system drainage ${ }^{19}$. Refractory hematomas which was recurrent more than twice, may require subduroperitoneal shunt, a reservoir with serial tapping, or middle meningeal artery embolization. Even in refractory CSDHs, subduroperitoneal shunt or middle meningeal artery embolization is less invasive than craniotomy. Some authors recommended endoscopic removal ${ }^{13,29)}$, continuous postoperative irrigation and drainage ${ }^{96)}$, or injection of isotonic fluid into the ventricular space to promote brain re-expansion for refractory hematomas ${ }^{70}$, the impact of these measures is controversial.

The method of anesthesia depends on the method of surgery. General anesthesia is necessary for long operation with large skin incision. Local anesthesia is usually sufficient with percutaneous drainage ${ }^{2}$. In general, general anesthesia may cause cardiovascular or respiratory complications, while local anesthesia may reduce the duration of drainage or hospital stay. However, local anesthesia is safe for cooperative patients or patients with high risk systemic disorders which prevent general anesthesia. Anesthetic method also depends on the patient condition.

\section{DETAILS OF SURGICAL METHODS}

There was a report ${ }^{85}$ that one $\mathrm{BH}$ only was associated with a significantly higher recurrence rate, longer hospital stay and higher infection rate. A meta-analysis suggested that single $\mathrm{BH}$ is as good as double $\mathrm{BHs}^{9}$. Another $\mathrm{BH}$ is usually not necessary.

Irrigation of the hematoma cavity may dilute anticoagulating substances such as fibrin degradation product, which may reduce the chance of recurrence. However, air intrusion during irrigation may cause tension pneumocephalus, headache, or recurrence ${ }^{41}$. Irrigation itself may cause cortical injury or bleeding ${ }^{96)}$. It is not necessary for all CSDHs, although it may be helpful when the hematoma has solid mass ${ }^{977}$.

Removal of the membranes after craniotomy is to eradicate the bleeding source and to facilitate re-expansion of the brain. Membranectomy was often recommended when there was solid hematomas with various bleeding foci, multilayer loculations within the hematoma, and excessive formation of a solid membranes $^{399}$. However, membranectomy carries a distinctly higher risk of rebleeding, especially membranes surrounding the bridge veins and the area of tenacious adherence between inner membrane and arachnoid surface ${ }^{44,71}$. Even in hematomas with multiple septations, it is not necessary to remove the membrane. The result of surgery and the rate of recurrence was not influenced by the membranectomy or partial tearing of the membranes. Aggressive removal of membranes may cause cortical injury, which evokes postoperative convulsive disorder ${ }^{71)}$.

Drain is very useful to remove the remained hematoma slowly. However, prolonged placement of the drain may raise the infection rate ${ }^{53)}$. Drainage for 48 hours has the advantage of reducing recurrence without increasing complications ${ }^{1,43,50,75)}$. Postoperative position whether supine or sitting, did not show any differences in the recurrence rate ${ }^{58)}$. However, early mobilization is recommended to avoid complications related prolonged recumbence. Postoperative physical activity is usually not limited in patients with chronic subdural hematoma. However, it would be desirable to avoid a certain exercise, which may cause shaking of the head. Postoperative CT scan is often useful to confirm the result of surgery, however, routine CT around 4-6 weeks after surgery is not recommended $^{64)}$. 


\section{ALTERNATIVE METHODS}

Subdural tapping is useful in infants ${ }^{4}$. It can be available in children or even in adults. If the skull is hard to penetrate by the needle, a path can be made by a hand drill ${ }^{69)}$. The endoscopic treatment of septated or organized CSDH represents a minimally invasive alternative to craniotomy especially for the internal membranectomy ${ }^{13,71)}$. Endoscopic management is not popular since fibrin septa or thick inner membranes hindering drainage represents less than $5 \%$ of all CSDH. Actually, membranectomy is seldom required for brain re-expansion. Thrombolytic agent is often useful to remove partially resolved hematomas ${ }^{5}$.

Mini-craniotomy, the diameter of the bone flap remains limited to 3-4 cm, may have superior visualization, while the invasiveness and complication rate are equal to those of $\mathrm{BH}^{87}$. There was a report of lower recurrences with mini-craniotomy, however, this technique is not recommended since the removal of the membranes doesn't precipitate the brain re-expansion.

Subduroperitoneal shunts, though rarely used, may be a viable option in the treatment of CSDH, especially in refractory cases $^{88)}$. However, the shunt requires a device implanted into the peritoneal cavity, which needs general anesthesia. Furthermore it requires consistent monitoring and often fail. Previously, it was useful for pediatric CSDHs, or older patients with recurrent or thick membranes ${ }^{66,88)}$. This method may be reserved for refractory or cases of at least three times recurrence. There are some modified techniques such as implantation of a reservoir $^{76)}$, continuous subgaleal suction drainage ${ }^{24)}$, or a Ttube drainage ${ }^{51)}$. Although they may reduce additional operations ${ }^{43)}$, these modifications failed to get popularity.

Recently embolization of the middle meningeal artery (EMMA) with or without trephination was reported as an effective method ${ }^{49)}$. Although EMMA interrupts the blood supply to the outer membrane and thus prevents hematoma enlargement, it often fails to prevent recurrences ${ }^{16}$. Sufficient subdural space is the key factor for development of CSDH. Theoretically, elimination of the subdural space is fundamental than prevention of hematoma enlargement to prevent the recurrence. To reduce the subdural space, lumbar or ventricular injection at the time of operation and/or afterward is effective and safe for immediate cerebral re-expansion ${ }^{27}$. Since trephination with closed system drainage is easy, safe and effective, lumbar or ventricular injection is seldom used. Refractory CSDHs may require complete obliteration of the subdural hematoma cavity by reducing the dura or fibrin glue injection ${ }^{61,92)}$. When there is a macrocephaly from expanding $\mathrm{CSDH}$, reduction cranioplasty may become the last choice ${ }^{55,81)}$. Fortunately, such cases are extremely rare.

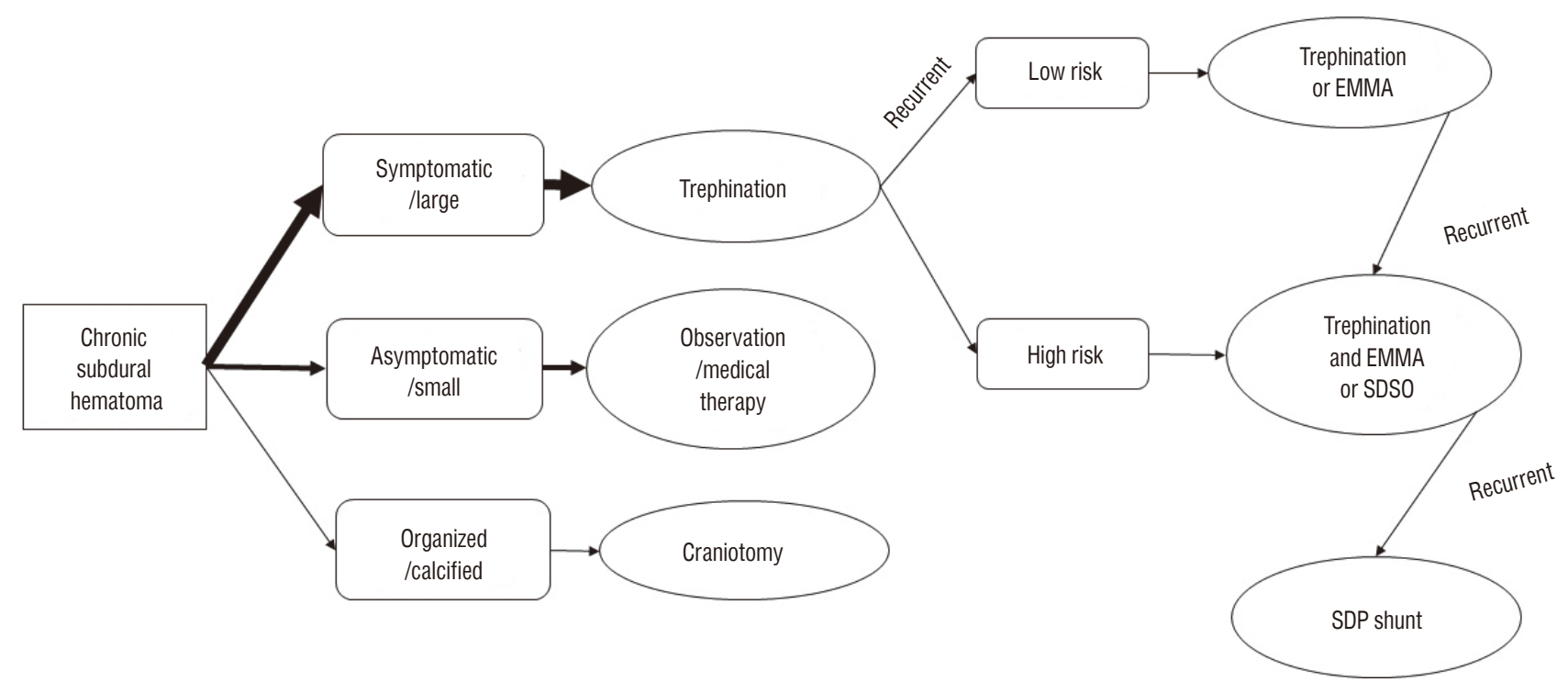

Fig. 1. Algorithm for practical management of chronic subdural hematoma. EMMA : embolization of middle meningeal artery, SDSO : subdural space obliteration, SDP : subduroperitoneal. 


\section{ALGORITHM FOR MANAGEMENT}

Up to date, trephination either by BH or TD is the treatment of choice for symptomatic patients (Fig. 1). Craniotomy should be reserved only for symptomatic organized or solid hematomas. For the recurrent CSDHs, if the risk of recurrence is low, still repeated trephination is simple and effective. If the risk of recurrence is high, additional management such as EMMA may reduce the chance of recurrence. Oslo grading system $^{79)}$ seems to be very useful to predict the risk of recurrence. For the refractory CSDHs, it is necessary to obliterate the subdural space by lumbar or ventricular injection, fibrin glue injection or reducing the dura. Subduroperitoneal shunts can be the last choice for refractory CSDHs. If there is a new easy and safe therapy, we should change this algorithm.

\section{CONCLUSION}

Nonsurgical treatment is possible in asymptomatic patients with a small CSDH. For the symptomatic patients with CSDH, trephination is the treatment of choice, either by $\mathrm{BH}$ or TD. In gray zone between surgery and medical treatment, shared decision making can be an ideal approach. For the recurrent CSDHs, repeated trephination is still effective for patients with a low risk of recurrence. If the risk of recurrence is high, additional management would be helpful. For the refractory CSDHs, it is necessary to obliterate the subdural space.

\section{CONFLICTS OF INTEREST}

No potential conflict of interest relevant to this article was reported.

\section{INFORMED CONSENT}

This type of study does not require informed consent.

\section{References}

1. Alcalá-Cerra G, Young AM, Moscote-Salazar LR, Paternina-Caicedo Á :
Efficacy and safety of subdural drains after burr-hole evacuation of chronic subdural hematomas: systematic review and meta-analysis of randomized controlled trials. World Neurosurg 82 : 1148-1157, 2014

2. Almenawer SA, Farrokhyar F, Hong C, Alhazzani W, Manoranjan B, Yarascavitch $B$, et al. : Chronic subdural hematoma management: a systematic review and meta-analysis of 34,829 patients. Ann Surg 259 : 449-457, 2014

3. Ambrosetto C : Post-traumatic subdural hematoma. Further observations on nonsurgical treatment. Arch Neurol 6 : 287-292, 1962

4. Aoki $\mathbf{N}$ : Chronic subdural hematoma in infancy. Clinical analysis of 30 cases in the CT era. J Neurosurg 73 : 201-205, 1990

5. Arginteanu MS, Byun $\mathrm{H}$, King W : Treatment of a recurrent subdural hematoma using urokinase. J Neurotrauma 16 : 1235-1239, 1999

6. Asfora WT, Schwebach L : A modified technique to treat chronic and subacute subdural hematoma: technical note. Surg Neurol 59 : 329332; discussion 332, 2003

7. Barry MJ, Edgman-Levitan S : Shared decision making--pinnacle of patient-centered care. N Engl J Med 366 : 780-781, 2012

8. Baschera D, Tosic L, Westermann L, Oberle J, Alfieri A : Treatment standards for chronic subdural hematoma: results from a survey in Austrian, German and Swiss neurosurgical units. World Neurosurg 116 : e983e995, 2018

9. Belkhair $\mathrm{S}$, Pickett $\mathrm{G}$ : One versus double burr holes for treating chronic subdural hematoma meta-analysis. Can J Neurol Sci 40 : 56-60, 2013

10. Bender $\mathrm{MB}$, Christoff $\mathrm{N}$ : Nonsurgical treatment of subdural hematomas. Arch Neurol $31:$ 73-79, 1974

11. Berghauser Pont LM, Dippel DW, Verweij BH, Dirven CM, Dammers R : Ambivalence among neurologists and neurosurgeons on the treatment of chronic subdural hematoma: a national survey. Acta Neurol Belg $113:$ 55-59, 2013

12. Berghauser Pont LM, Dirven CM, Dippel DW, Verweij BH, Dammers R : The role of corticosteroids in the management of chronic subdural hematoma: a systematic review. Eur J Neurol 19 : 1397-1403, 2012

13. Berhouma $M$, Jacquesson $T$, Jouanneau $E$ : The minimally invasive endoscopic management of septated chronic subdural hematomas: surgical technique. Acta Neurochir (Wien) 156 : 2359-2362, 2014

14. Bleck TP : Historical aspects of critical care and the nervous system. Crit Care Clin 25 : 153-164, ix, 2009

15. Cenic A, Bhandari M, Reddy K : Management of chronic subdural hematoma: a national survey and literature review. Can J Neurol Sci 32 : 501-506, 2005

16. Chihara H, Imamura H, Ogura T, Adachi H, Imai Y, Sakai N : Recurrence of a refractory chronic subdural hematoma after middle meningeal artery embolization that required craniotomy. NMC Case Rep J 1 : 1-5, 2014

17 Delgado-López PD, Martín-Velasco V, Castilla-Díez JM, Rodríguez-Salazar A, Galacho-Harriero AM, Fernández-Arconada 0 : Dexamethasone treatment in chronic subdural haematoma. Neurocirugia $20: 346$ 359, 2009

18. D'Errico AP, German WJ : Chronic subdural hematoma. Yale J Biol Med $3: 11-20,1930$ 
19. Desai VR, Scranton RA, Britz GW : Management of recurrent subdural hematomas. Neurosurg Clin N Am 28 : 279-286, 2017

20. Ducruet AF, Grobelny BT, Zacharia BE, Hickman ZL, DeRosa PL, Anderson $\mathrm{KN}$, et al. : The surgical management of chronic subdural hematoma. Neurosurg Rev 35 : 155-169; discussion 169, 2012

21. Emich S, Richling B, McCoy MR, Al-Schameri RA, Ling F, Sun L, et al. : The efficacy of dexamethasone on reduction in the reoperation rate of chronic subdural hematoma--the DRESH study: straightforward study protocol for a randomized controlled trial. Trials $15: 6,2014$

22. Emonds $N$, Hassler WE : New device to treat chronic subdural hematoma--hollow screw. Neurol Res 21 : 77-78, 1999

23. Frazier $\mathrm{CH}$ : The surgical management of chronic subdural hematoma. Ann Surg 101 : 671-689, 1935

24. Gazzeri R, Galarza M, Neroni M, Canova A, Refice GM, Esposito S : Continuous subgaleal suction drainage for the treatment of chronic subdural haematoma. Acta Neurochir (Wien) 149 : 487-493; discussion 493, 2007

25. Gelabert-González M, Iglesias-Pais M, García-Allut A, Martínez-Rumbo $R$ : Chronic subdural haematoma: surgical treatment and outcome in 1000 cases. Clin Neurol Neurosurg 107 : 223-229, 2005

26. Gjerris F, Schmidt K : Chronic subdural hematoma. Surgery or mannitol treatment. J Neurosurg $40: 639-642,1974$

27. Grisoli F, Graziani N, Peragut JC, Vincentelli F, Fabrizi AP, Caruso G, et al. : Perioperative lumbar injection of Ringer's lactate solution in chronic subdural hematomas: a series of 100 cases. Neurosurgery $23: 616$ 621,1988

28. Gurelik M, Aslan A, Gurelik B, Ozum U, Karadag Ö, Kars HZ : A safe and effective method for treatment of chronic subdural haematoma. Can J Neurol Sci 34 : 84-87, 2007

29. Hellwig D, Kuhn TJ, Bauer BL, List-Hellwig E : Endoscopic treatment of septated chronic subdural hematoma. Surg Neurol 45 : 272-277, 1996

30. Hirakawa K, Hashizume K, Fuchinoue T, Takahashi H, Nomura K : Statistical analysis of chronic subdural hematoma in 309 adult cases. Neurol Med Chir (Tokyo) $12:$ 71-83, 1972

31. Horikoshi T, Naganuma H, Fukasawa I, Uchida M, Nukui H : Computed tomography characteristics suggestive of spontaneous resolution of chronic subdural hematoma. Neurol Med Chir (Tokyo) 38 : 527-532; discussion 532-523, 1998

32. Horn EM, Feiz-Erfan I, Bristol RE, Spetzler RF, Harrington TR : Bedside twist drill craniostomy for chronic subdural hematoma: a comparative study. Surg Neurol 65 : 150-153; discussion 153-154, 2006

33. Horrax G, Poppen JL : The frequency, recognition and treatment of chronic subdural hematomas. N Engl J Med 216 : 381-385, 1937

34. Ivamoto HS, Lemos HP Jr, Atallah AN : Surgical treatments for chronic subdural hematomas: a comprehensive systematic review. World Neurosurg $86: 399-418,2016$

35. Jamieson KG : Extradural and subdural hematomas. Changing patterns and requirements of treatment in Australia. J Neurosurg 33 : 632-635, 1970

36. Kageyama H, Toyooka T, Tsuzuki N, Oka K : Nonsurgical treatment of chronic subdural hematoma with tranexamic acid. J Neurosurg 119 :
332-337, 2013

37. Kenning TJ, Dalfino JC, German JW, Drazin D, Adamo MA : Analysis of the subdural evacuating port system for the treatment of subacute and chronic subdural hematomas. J Neurosurg 113 : 1004-1010, 2010

38. Kim HC, Ko JH, Yoo DS, Lee SK : Spontaneous resolution of chronic subdural hematoma: close observation as a treatment strategy. J Korean Neurosurg Soc 59 : 628-636, 2016

39. Kim JH, Kang DS, Kim JH, Kong MH, Song KY : Chronic subdural hematoma treated by small or large craniotomy with membranectomy as the initial treatment. J Korean Neurosurg Soc 50 : 103-108, 2011

40. Krieg SM, Aldinger F, Stoffel M, Meyer B, Kreutzer J : Minimally invasive decompression of chronic subdural haematomas using hollow screws: efficacy and safety in a consecutive series of 320 cases. Acta Neurochir (Wien) 154 : 699-705; discussion 705, 2012

41. Kuroki T, Katsume M, Harada N, Yamazaki T, Aoki K, Takasu N : Strict closed-system drainage for treating chronic subdural haematoma. Acta Neurochir (Wien) 143 : 1041-1044, 2001

42. Kwon CS, Al-Awar O, Richards O, Izu A, Lengvenis G : Predicting prognosis of patients with chronic subdural hematoma: a new scoring system. World Neurosurg 109 : e707-e714, 2018

43. Laumer R, Schramm J, Leykauf $\mathrm{K}$ : Implantation of a reservoir for recurrent subdural hematoma drainage. Neurosurgery 25 : 991-996, 1989

44. Lee JY, Ebel $\mathrm{H}$, Ernestus RI, Klug $\mathrm{N}$ : Various surgical treatments of chronic subdural hematoma and outcome in 172 patients: is membranectomy necessary? Surg Neurol 61 : 523-527; discussion 527-528, 2004

45. Lee KS : History of chronic subdural hematoma. Korean J Neurotrauma $11: 27-34,2015$

46. Lee KS : Natural history of chronic subdural haematoma. Brain Inj 18 : 351-358, 2004

47. Lee SJ, Hwang SC, Im SB : Twist-drill or burr hole craniostomy for draining chronic subdural hematomas: how to choose it for chronic subdural hematoma drainage. Korean J Neurotrauma 12 : 107-111, 2016

48. Lega BC, Danish SF, Malhotra NR, Sonnad SS, Stein SC : Choosing the best operation for chronic subdural hematoma: a decision analysis. J Neurosurg 113 : 615-621, 2010

49. Link TW, Schwarz JT, Paine SM, Kamel H, Knopman J : Middle meningeal artery embolization for recurrent chronic subdural hematoma: a case series. World Neurosurg 118 : e570-e574, 2018

50. Liu W, Bakker NA, Groen RJ : Chronic subdural hematoma: a systematic review and meta-analysis of surgical procedures. J Neurosurg 121 : 665-673, 2014

51. Lu W, Wang H, Wu T, Sheng X, Ding Z, Xu G : Burr-hole Craniostomy with T-tube drainage as surgical treatment for chronic subdural hematoma. World Neurosurg 115 : e756-e760, 2018

52. Markwalder TM : Chronic subdural hematomas: a review. J Neurosurg 54 : 637-645, 1981

53. Markwalder TM, Seiler RW : Chronic subdural hematomas: to drain or not to drain? Neurosurgery $16: 185-188,1985$

54. Martin G : Trepanation in the South pacific. J Clin Neurosci 2 : 257264, 1995 
55. Matsui T, Tsutsumi K, Kaizu H, Asano T : Reduction cranioplasty for craniocerebral disproportion due to chronic subdural hematoma in infants. A technical report. Neurol Res 23 : 67-71, 2001

56. Montano N, loannoni E, Caricato A, Olivi A : Survey of available literature and meta-analyses on chronic subdural hematoma. Int J Med Rev $3:$ :497-500, 2018

57. Naganuma H, Fukamachi A, Kawakami M, Misumi S, Nakajima $H$, Wakao $T$ : Spontaneous resolution of chronic subdural hematomas. Neurosurgery 19 : 794-798, 1986

58. Nakajima H, Yasui T, Nishikawa M, Kishi H, Kan M : The role of postoperative patient posture in the recurrence of chronic subdural hematoma: a prospective randomized trial. Surg Neurol 58 : 385-387; discussion 387, 2002

59. Neal MT, Hsu W, Urban JE, Angelo NM, Sweasey TA, Branch CL Jr : The subdural evacuation port system: outcomes from a single institution experience and predictors of success. Clin Neurol Neurosurg 115 : 658-664, 2013

60. Negrón RA, Tirado G, Zapater C : Simple bedside technique for evacuating chronic subdural hematomas. Technical note. J Neurosurg 42 : 609-611, 1975

61. Oku Y, Takimoto N, Yamamoto K, Onishi T : Trial of a new operative method for recurrent chronic subdural hematoma. J Neurosurg 61 : 269-272, 1984

62. Oshima Lee E, Emanuel EJ : Shared decision making to improve care and reduce costs. N Engl J Med $368:$ 6-8, 2013

63. Parlato C, Guarracino A, Moraci A : Spontaneous resolution of chronic subdural hematoma. Surg Neurol 53 : 312-315; discussion 315-317, 2000

64. Pedersen $C B$, Sundbye F, Poulsen FR : No value of routine brain computed tomography 6 weeks after evacuation of chronic subdural hematoma. Surg J (N Y) 3 : e174-e176, 2017

65 Prevedi G : Roentgen-therapy of subacute and chronic subdural hematomas controlled by carotid angiography. Radiol Med 52 : 436-447, 1966

66. Probst $\mathrm{C}$ : Peritoneal drainage of chronic subdural hematomas in older patients. J Neurosurg 68 : 908-911, 1988

67. Putnam TJ, Cushing $\mathrm{H}$ : Chronic subdural hematoma: its pathology, its relation to pachymeningitis hemorrhagica and its surgical treatment. Archi Surg 11 : 329-393, 1925

68. Ratre S, Yadav Y, Choudhary S, Parihar V : Spontaneous resolution of chronic subdural haematoma in a patient receiving anticoagulant therapy. J Assoc Physicians India 63 : 79-80, 2015

69. Reinges MH, Hasselberg I, Rohde V, Küker W, Gilsbach JM : Prospective analysis of bedside percutaneous subdural tapping for the treatment of chronic subdural haematoma in adults. J Neurol Neurosurg Psychiatry $69: 40-47,2000$

70. Robinson RG : Chronic subdural hematoma: surgical management in 133 patients. J Neurosurg 61 : 263-268, 1984

71. Rocchi G, Caroli E, Salvati M, Delfini R : Membranectomy in organized chronic subdural hematomas: indications and technical notes. Surg Neurol 67 : 374-380; discussion 380, 2007
72. Rovlias A, Theodoropoulos S, Papoutsakis D : Chronic subdural hematoma: surgical management and outcome in 986 cases: a classification and regression tree approach. Surg Neurol Int $6:$ 127, 2015

73. Rudiger A, Ronsdorf A, Merlo A, Zimmerli W : Dexamethasone treatment of a patient with large bilateral chronic subdural haematomata. Swiss Med Wkly $131:$ 387, 2001

74. Rughani Al, Lin C, Dumont TM, Penar PL, Horgan MA, Tranmer BI : A case-comparison study of the subdural evacuating port system in treating chronic subdural hematomas. J Neurosurg 113 : 609-614, 2010

75. Santarius T, Lawton R, Kirkpatrick PJ, Hutchinson PJ : The management of primary chronic subdural haematoma: a questionnaire survey of practice in the United Kingdom and the Republic of Ireland. Br J Neurosurg 22 : 529-534, 2008

76. Sato M, Iwatsuki K, Akiyama C, Kumura E, Yoshimine T : Implantation of a reservoir for refractory chronic subdural hematoma. Neurosurgery 48 : 1297-1301, 2001

77. Singla A, Jacobsen WP, Yusupov IR, Carter DA : Subdural evacuating port system (SEPS)--minimally invasive approach to the management of chronic/subacute subdural hematomas. Clin Neurol Neurosurg 115 : 425-431, 2013

78. Soleman J, Taussky P, Fandino J, Muroi C : Evidence-based treatment of chronic subdural hematoma in Sadaka DF (ed) : Traumatic Brain Injury, ed 1. London : InTech, 2014, pp249-282

79. Stanišic M, Pripp AH : A reliable grading system for prediction of chronic subdural hematoma recurrence requiring reoperation after initial burrhole surgery. Neurosurgery $81: 752-760,2017$

80. Sun TF, Boet R, Poon WS : Non-surgical primary treatment of chronic subdural haematoma: preliminary results of using dexamethasone. $\mathbf{B r} \mathbf{J}$ Neurosurg $19:$ 327-333, 2005

81. Sundine MJ, Wirth GA, Brenner KA, Loudon WG, Muhonen MG, Greene CS, et al. : Cranial vault reduction cranioplasty in children with hydrocephalic macrocephaly. J Craniofac Surg 17 : 645-655, 2006

82. Suzuki J, Takaku A : Nonsurgical treatment of chronic subdural hematoma. J Neurosurg 33 : 548-553, 1970

83. Suzuki K, Sugita K, Akai T, Takahata T, Sonobe M, Takahashi S : Treatment of chronic subdural hematoma by closed-system drainage without irrigation. Surg Neurol 50 : 231-234, 1998

84. Tabaddor K, Shulman K : Definitive treatment of chronic subdural hematoma by twist-drill craniostomy and closed-system drainage. J Neurosurg 46 : 220-226, 1977

85. Taussky P, Fandino J, Landolt $\mathrm{H}$ : Number of burr holes as independent predictor of postoperative recurrence in chronic subdural haematoma. Br J Neurosurg 22 : 279-282, 2008

86. Thotakura AK, Marabathina NR : Nonsurgical treatment of chronic subdural hematoma with steroids. World Neurosurg 84 : 1968-1972, 2015

87. Van Der Veken J, Duerinck J, Buyl R, Van Rompaey K, Herregodts P, D'Haens J : Mini-craniotomy as the primary surgical intervention for the treatment of chronic subdural hematoma--a retrospective analysis. Acta Neurochir (Wien) $156:$ 981-987, 2014

88. Vinchon $M$, Noulé $N$, Soto-Ares $G$, Dhellemmes $P$ : Subduroperitoneal 
drainage for subdural hematomas in infants: results in 244 cases. J Neurosurg 95 : 249-255, 2001

89. Voelker JL : Nonoperative treatment of chronic subdural hematoma. Neurosurg Clin N Am 11 : 507-513, 2000

90. Wang D, Li T, Tian Y, Wang S, Jin C, Wei H, et al. : Effects of atorvastatin on chronic subdural hematoma: a preliminary report from three medical centers. J Neurol Sci 336 : 237-242, 2014

91. Wang QF, Cheng C, You C : A new modified twist drill craniostomy using a novel device to evacuate chronic subdural hematoma. Medicine (Baltimore) 95 : e3036, 2016

92. Watanabe S, Amagasaki K, Shono N, Nakaguchi H : Fibrin glue injection into the hematoma cavity for refractory chronic subdural hematoma: a case report. Surg Neurol Int 7 (Suppl 37) : S876-S879, 2016

93. Weigel $R$, Hohenstein A, Schlickum L, Weiss C, Schilling L : Angiotensin converting enzyme inhibition for arterial hypertension reduces the risk of recurrence in patients with chronic subdural hematoma possibly by an antiangiogenic mechanism. Neurosurgery 61 : 788-792; discussion
792-793, 2007

94. Weigel R, Krauss JK, Schmiedek P : Concepts of neurosurgical management of chronic subdural haematoma: historical perspectives. Br J Neurosurg $18: 8-18,2004$

95. Weigel $R$, Schmiedek P, Krauss JK : Outcome of contemporary surgery for chronic subdural haematoma: evidence based review. J Neurol Neurosurg Psychiatry 74 : 937-943, 2003

96. Xu C, Chen S, Yuan L, Jing Y : Burr-hole irrigation with closed-system drainage for the treatment of chronic subdural hematoma: a metaanalysis. Neurol Med Chir (Tokyo) 56 : 62-68, 2016

97. Xu CS, Lu M, Liu LY, Yao MY, Cheng GL, Tian XY, et al. : Chronic subdural hematoma management: clarifying the definitions of outcome measures to better understand treatment efficacy - a systematic review and meta-analysis. Eur Rev Med Pharmacol Sci 21 : 809-818, 2017

98. Yamada SM, Tomita Y, Murakami H, Nakane M, Yamada S, Murakami M, et al. : Headache in patients with chronic subdural hematoma: analysis in 1080 patients. Neurosurg Rev 41 : 549-556, 2018 